\title{
COMMENTARY
}

\section{Do men perform better than women in trauma?}

\author{
Alberto Hernández-Tejedor ${ }^{1 *}$, Carlos García-Fuentes ${ }^{2}$ and Emilio Alted-López ${ }^{2}$ \\ See related research by Schoeneberg et al., http://ccforum.com/content/17/6/R277
}

\begin{abstract}
In recent decades, numerous studies have compared survival according to gender of patients admitted to general hospitals and particularly to intensive care units. In a previous issue of Critical Care, Schoeneberg and colleagues presented the results of a German observational study on a sample from a 10 year registry in a Level 1 trauma center. The conclusion is that there is a trend towards a higher mortality in women than in men.
\end{abstract}

Epidemiological studies provide insight into certain features of diseases that may be useful when developing preventative or treatment strategies. Not only trauma but many other diseases have been studied, comparing and analyzing the different course in men and women, giving rise to various hypotheses. In a previous issue of Critical Care, Schoeneberg and colleagues [1] report their results of a study comparing outcome according to gender of severe trauma patients admitted to a Level 1 trauma center in Germany.

Firstly, we should appreciate that the prevalence of different injury mechanisms can be different in males and females, with a higher frequency of stab and traffic accident injuries in males. The injury pattern is different according to gender since most injuries occur in environments and circumstances that show differences in behavior between men and women, such as leisure, workplace or the use of motor vehicles [2]. Also, as expected, differences in mortality between men and women become smaller when only patients with very high Injury Severity Scores are considered, as mortality is usually inevitable in these extremely serious injuries.

Schoeneberg and colleagues [1] have conducted numerous comparisons, increasing the likelihood that

\footnotetext{
* Correspondence: albertohmed@hotmail.com

'Unidad de Cuidados Críticos, Hospital Universitario Fundación Alcorcón, C/. Budapest, 1, 28922 Alcorcón (Madrid), Spain

Full list of author information is available at the end of the article
}

some of them show a statistically significant result. In particular, absolute volumes of fluid replacement administered are lower in women than in men, but women usually have a lower body weight, so that the volume administered per body weight may not be different. Hemoglobin concentration at admission is also lower in women than men, although this may not reflect a more severe hemorrhage but a lower baseline value (hemoglobin concentration is typically lower in healthy women than men, mainly in childbearing age). Although the analysis shows a trend towards a higher mortality in women in most of the analyzed subgroups, when potential confounders are adjusted for, such as age or Abbreviated Injury Scale, these differences are no longer statistically significant.

Gender comparisons in general populations of critically ill patients have come to divergent conclusions, but improved survival in women probably predominates $[3,4]$. These observations have led to numerous hypotheses, usually around hormonal differences or immune issues $[5,6]$. In the case of multiple trauma patients, similar studies have been performed but most have concluded that overall mortality is not influenced by gender $[7,8]$. These studies are usually single-institution studies, so conclusions cannot be drawn about population genotypic differences that may lead to different results depending, for example, on race.

In an attempt to find a practical reason for the observed differences, animal studies have been conducted and suggest that female sex hormones can be neuroprotective. In fact, several studies document improved neuronal survival with administration of estrogen or progesterone to males or ovariectomized females $[9,10]$. However, exogenous administration of sex hormones may not replicate the natural effects - and assumed benefits - of the menstrual cycle.

One cannot conclude that there is definitely higher mortality in injured women than men, although there is such a tendency. Other factors may mitigate the influence of gender in trauma.

() Biomed Central

(c) 2014 Hernández-Tejedor et al.; licensee BioMed Central Ltd. The licensee has exclusive rights to distribute this article, in any medium, for 12 months following its publication. After this time, the article is available under the terms of the Creative Commons Attribution License (http://creativecommons.org/licenses/by/4.0), which permits unrestricted use, distribution, and reproduction in any medium, provided the original work is properly cited. 


\section{Competing interests}

The authors declare that they have no competing interests.

\section{Author details}

'Unidad de Cuidados Críticos, Hospital Universitario Fundación Alcorcón, C/. Budapest, 1, 28922 Alcorcón (Madrid), Spain. ${ }^{2}$ Unidad de Cuidados Intensivos, Hospital Universitario, 12 de Octubre Av, Córdoba s/n. 28041 Madrid, Spain.

\section{Published: 27 Feb 2014}

\section{References}

1. Schoeneberg C, Kauther MD, Hussmann B, Keitel J, Schmitz D, Lendemans S: Gender-specific differences in severely injured patients between 2002 and 2011: data analysis with matched-pair analysis. Crit Care 2013, 17:R277.

2. Hernández-Tejedor A, García-Fuentes C, Toral-Vázquez D, Chico-Fernández M, Alted-López E: Differences in injury mechanism and pattern, severity and outcome of multiple trauma patients depending on gender. Med Intensiva 2008, 32:337-341.

3. Gordon HS, Rosenthal GE: The relationship of gender and in-hospital death: increased risk of death in men. Med Care 1999, 37:318-324.

4. Kollef MH, O'Brien JD, Silver P: The impact of gender on outcome from mechanical ventilation. Chest 1997, 111:434-441.

5. Angele MK, Ayala A, Monfils BA, Cioffi WG, Bland Kl, Chaudry $\mathrm{H}$ : Testosterone and/or low estradiol: normally required but harmful immunologically for males after trauma-hemorrhage. J Trauma 1998, 44:78-85.

6. Roof RL, Hall ED: Gender differences in acute CNS trauma and stroke: neuroprotective effects of estrogen and progesterone. J Neurotrauma 2000, 17:367-388.

7. Rappold JF, Coimbra R, Hoyt DB, Potenza BM, Fortlage D, Holbrook T: Female gender does not protect blunt trauma patients from complications and mortality. J Trauma 2002, 53:436-441.

8. Mostafa G, Huynh T, Sing RF, Miles WS, Norton HJ, Thomason MH: Gender-related outcomes in trauma. J Trauma 2002, 53:430-435.

9. Shear DA, Galani R, Hoffman SW, Stein DG: Progesterone protects against necrotic damage and behavioral abnormalities caused by traumatic brain injury. Exp Neurol 2002, 178:59-67.

10. Suzuki T, Bramlett HM, Ruenes G, Dietrich WD: The effects of early post-traumatic hyperthermia in female and ovariectomized rats. J Neurotrauma 2004, 21:842-853.

\section{$10.1186 / \mathrm{cc} 13748$}

Cite this article as: Hernández-Tejedor et al:: Do men perform better than women in trauma? Critical Care 2014, 18:114 